\title{
JPEB
}

Jurnal Penelitian Ekonomi dan Bisnis, 4 (1), 2019, Hal: 52 - 64

http://www.jpeb.dinus.ac.id

\section{KEPEMIMPINAN PELAYANAN, BUDAYA ORGANISASI DAN PENGARUHNYA PADA PROAKTIVITAS DAN KINERJA KARYAWAN}

\author{
Artha Febriana* \\ Jurusan Manajemen, Fakultas Ekonomika dan Bisnis, Universitas Dian Nuswantoro \\ Jalan Nakula I No. 5-11 Semarang, Indonesia \\ *Corresponding Author: artha.febriana@,dsn.dinus.ac.id
}

Diterima: Desember 2018 ; Direvisi: Januari 2019 ; Dipublikasikan: Maret 2019

\begin{abstract}
This study aims to provide influence between servant leadership variables and organizational culture on employee performance with proactivity as a mediating variable. 265 employees were used with purposive sampling technique. Based on the results of SEM testing on the five hypotheses, the first hypotheses states that the stronger servant leadership, the higher the effect of proactivity can be received with a significance value 0.049. In the second, third, fourth and fifth hypotheses stating that the stronger servant leadership and organizational culture, the higher the effect on proactivity and employee performance can be received with a significance value 0.001. Based on these results it can be concluded that proactivity is able to mediate the causal relationship of servant leadership variables on employee performance and organizational culture on employee performance in electronic companies in Central Java.
\end{abstract}

Keyword: Servant Leadership; Organizational Culture; Proactivity; Employee Performance

\begin{abstract}
ABSTRAK
Penelitian ini bertujuan untuk memberikan pengaruh antara variabel kepemimpinan pelayanan dan budaya organisasi terhadap kinerja karyawan dengan proaktivitas sebagai variabel pemediasi. Sampel yang digunakan sebanyak 265 karyawan dengan teknik purposive sampling. Berdasarkan hasil pengujian SEM pada kelima hipotesis, hipotesis pertama menyatakan bahwa semakin kuat kepemimpinan pelayanan maka semakin tinggi pengaruh proaktivitas dapat diterima ditunjukkan dengan nilai signifikansi 0.049. Pada hipotesis kedua, ketiga, keempat dan kelima menyatakan bahwa semakin kuat kepemimpinan pelayanan dan budaya organisasi maka semakin tinggi pula pengaruh proaktivitas dan kinerja karyawan dapat diterima dengan nilai signifikansi 0.001 . Berdasarkan hasil tersebut dapat disimpulkan bahwa proaktivitas mampu memediasi hubungan kausalitas variabel kepemimpinan pelayanan terhadap kinerja karyawan dan budaya organisasi terhadap kinerja karyawan pada perusahaan elektronik di Jawa Tengah.
\end{abstract}

Kata Kunci: Kepemimpinan Pelayanan; Budaya Organisasi; Proaktivitas; Kinerja Karyawan. 


\section{PENDAHULUAN}

Industri elektronik dan perlengkapan listrik adalah industri utama dan merupakan sektor yang paling cepat pertumbuhannya secara global. Sekarang ini, elektronik bukan lagi sebuah media namun menjadi kebutuhan dan life style masyarakat (Simanjuntak, 2010). Tingginya kebutuhan akan life style dalam masyarakat menyebabkan permintaan produk elektronik dan perlengkapan listrik menjadi tinggi.

Keberhasilan dan kegagalan perusahaan sebagian besar ditentukan oleh gaya kepemimpinan seseorang dalam mengelola sumber daya yang ada, dan dari gaya kepemimpinan inilah suasana lingkungan kerja ditentukan (Burns, 1978; Bass, 1985). Menurut Linton (2003) keberhasilan seorang pemimpin terkait dengan kemampuannya untuk mempengaruhi atau membujuk secara interpersonal yang membuat sekelompok orang mau melakukan perintah dan bekerjasama karena mereka ingin, bukan karena keterpaksaan. Dimana pemimpin perlu membina hubungan manusia (human relations) yang baik dan merangsang bawahannya untuk berani mengambil keputusan yang wajar dalam situasi yang menyenangkan (Omolayo, 2007; Chung, 2009).

Temuan penelitian Wang et al., (2009) menunjukkan bahwa pemimpin yang mencapai kesuksesan bukan sebagai individu, tetapi melalui kemampuannya dalam bekerja dengan anggota. Berbagai penelitian terdahulu mengkonfirmasi bahwa perusahaan dengan kepemimpinan yang kuat dan efektif akan mencapai hasil bisnis yang superior (Jeremy dan Ciller, 2012). Pemimpin sebagai agen perubahan mengubah perilaku, struktur, dan prosedur demi akselerasi terhadap tujuan yang diinginkan (Oladipo, 2013). Perubahan prosedur atau cara kerja sebagai sarana atau alat untuk membuat perusahaan bekerja secara aktif, efektif, dan efisien (Lashbrook, 1997).

Namun pada kenyataannya masih terdapat selisih atau gap dalam usaha pencapaian target laba dengan realisasi laba yang dialami perusahaan. Hal ini disebabkan oleh ketidaknyamanan anggota dalam bekerja sehingga mereka akan bekerja pasif mencari aman dan tidak memberikan kontribusi apa-apa untuk kemajuan perusahaan. Anggota cenderung hanya akan menyelesaikan pekerjaan sesuai dengan deskripsi pekerjaan yang telah ditetapkan, dan pada akhirnya anggota akan mengganggu lingkungan dan iklim kerja. Pada kondisi seperti ini menimbulkan permasalahan bagi pimpinan dalam membangun sinergitas dengan menciptakan suasana kerja yang solid. Tujuan penelitian ini adalah menguji pengaruh kepemimpinan pelayanan dan budaya organisasi pada proaktivitas dan kinerja karyawan.

\section{TINJAUAN PUSTAKA}

\section{Kepemimpinan Pelayanan}

Kepemimpinan pelayanan adalah kemampuan untuk memengaruhi orang lain atau bawahannya agar mau bekerja sama untuk mencapai tujuan-tujuan tertentu (Conger dan Kanungo, 1988). Dikatakan pula bahwa kepemimpinan pelayanan adalah proses pemimpin dalam mempengaruhi bawahannya untuk (1) menginterprestasikan keadaan lingkungan organisasi; (2) pemilihan tujuan organisasi; (3) pengorganisasian kerja dan memotivasi bawahan untuk mencapai tujuan organisasi; (4) mempertahankan kerjasama dan tim kerja; (5) mengorganisasi dukungan dan kerjasama di luar organisasi (Greenleaf, 1991).

Fungsi kepemimpinan menurut beberapa peneliti adalah sebagai berikut: (1) menciptakan visi yaitu pemimpin dan bawahan merumuskan bersama ke arah peningkatan di masa mendatang, memotivasi dan memberikan energi untuk bergerak melakukan perubahan positif (Farling et al., 1999); (2) mengembangkan budaya organisasi yaitu pemimpin mengembangkan nilai-nilai baru, kemudian digunakan untuk memotivasi dan menggerakkan para bawahannya untuk mencapai tujuan (Russel dan Stone, 2002); (3) menciptakan sinergi yaitu pemimpin berperan untuk mempersatukan para bawahannya agar mampu menciptakan sinergi yang positif di masa mendatang (Sendjaya dan Sarros, 2002); (4) memberdayakan 
Artha Febriana : Kepemimpinan Pelayanan, Budaya Organisasi Dan Pengaruhnya Pada Proaktivitas Dan Kinerja Karyawan

bawahan merupakan tindakan membangun, mengembangkan dan meningkatkan daya atau kekuasaan melalui kerjasama, berbagi, dan bekerjasama (Stone et al, 2003); (5) menciptakan perubahan perilaku, struktur, prosedur, dan tujuan (Marcketti dan Kozae, 2007); (6) memotivasi bawahan (Linden et al., 2008); (7) mewakili sistem sosial yaitu pemimpin sebagai tokoh dan simbol yang tercermin dalam wajah, sikap, dan perilaku (Sendjaya et al, 2008); dan (8) pemimpin sebagai pembelajar organisasi yang mempunyai peran kritikal yaitu sebagai desainer (Valdiserri dan Wilson, 2010).

Dengan demikian indikator kepemimpinan menurut Greenleaf (1991) adalah sebagai berikut: (1) komunikasi, (2) kepedulian; (3) merangsang bawahan; (4) menjaga kekompakan; dan (5) menghargai perbedaan.

\section{Budaya organisasi}

Budaya organisasi adalah kumpulan nilai-nilai bersama, prinsip, dan tradisi yang mempengaruhi perilaku anggota organisasi dalam bekerja (Luthans, 1992).

Menurut Moorhead dan Griffin (1994) faktor utama yang menentukan kekuatan budaya organisasi adalah kebersamaan dan intensitas. Kebersamaan adalah sejauh mana anggota organisasi mempunyai nilai, prinsip, dan tradisi yang dianut secara bersama, dan intensitas adalah derajat komitmen dari anggota organisasi kepada nilai, prinsip dan tradisi organisasi.

Pendapat lain mengemukakan bahwa budaya organisasi sebagai bagian yang integral dan tak terpisahkan. Budaya organisasi yang kuat dan sejalan dengan visi, misi, serta selaras dengan tuntutan lingkungan akan mampu menciptakan lingkungan yang kondusif bagi perbaikan kinerja individu serta organisasi (Deal dan Kennedy, 1982).

Dengan demikian Schein (1991) menunjukkan bahwa indikator dari budaya organisasi adalah sebagai berikut: (1) kesadaran diri; (2) keagresifan; (3) kepribadian; (4) performa; dan (5) orientasi tim.

\section{Proaktivitas karyawan}

Proaktivitas didefinisikan sebagai perilaku karyawan yang secara aktif berinisiatif untuk memperbaiki keadaan atau menciptakan ide-ide baru di saat karyawan lain pasif dalam menghadapi berbagai situasi (Ashford dan Black, 1996). Proaktivitas terkait dengan kontribusi di atas dan lebih dari deskripsi pekerjaan (Bateman dan Crant 1993; Grant dan Ashford, 2008). Proaktivitas meliputi perilaku mendorong orang lain, menjadi volunteer untuk tugas-tugas ekstra, patuh terhadap aturan dan prosedur di tempat kerja. Perilakuperilaku ini menggambarkan nilai tambah karyawan dan merupakan salah satu bentuk perilaku yang positif, konstruktif dan bermakna membantu (Seibert, Crant dan Kraimer, 1999).

Sementara itu pendapat lain dikemukakan oleh Parker et al., (2010) bahwa perilaku proaktif dapat meningkatkan kemampuan organisasi untuk beradaptasi dengan perubahan lingkungan. Crant (2000) juga memberikan pengertian yang sama mengenai proaktivitas sebagai perilaku inisiatif dan antisipatif yaitu kemampuan mengambil inisiatif (kemampuan merencanakan sesuatu dengan segera) dan bersifat tanggap terhadap segala sesuatu yang sedang dan akan terjadi.

Dengan demikian Bateman dan Crant (1993) mengemukakan bahwa terdapat lima indikator dari proaktivitas meliputi: (1) inisiatif; (2) pemanfaatan peluang; (3) motivasi berprestasi; (4) fokus pada perubahan; dan (5) bertanggung jawab.

\section{Kinerja karyawan}

Audrey dan Patrice (2012) menyatakan bahwa kinerja adalah hasil dari suatu proses yang dapat dicapai seseorang atau sekelompok orang dalam suatu organisasi dalam rangka 
mencapai tujuan organisasi dalam periode waktu tertentu berdasarkan ketentuan atau kesepakatan yang telah ditetapkan sebelumnya.

Kinerja mengandung arti sebagai perbandingan antara hasil yang dicapai (output) dengan keseluruhan sumber daya yang digunakan (input) (Amstrong, 2006). Kinerja memiliki dua dimensi yaitu dimensi pertama adalah efektivitas yang mengarah kepada pencapaian target berkaitan dengan kualitas, kuantitas dan waktu (Baard et al., 2014). Yang kedua yaitu efisiensi yang berkaitan dengan upaya membandingkan input dengan realisasi penggunaannya atau bagaimana pekerjaan tersebut dilaksanakan (Baard et al., 2014).

Dengan demikian Amstrong (2006) menyatakan bahwa untuk mencapai atau menilai kinerja, ada indikator yang menjadi tolok ukur antara lain: (1) kualitas; (2) kuantitas; (3) ketepatan waktu; (4) kemandirian; dan (5) adaptabilitas.

Berikut model penelitian empiris yang dikembangkan dalam penelitian ini:

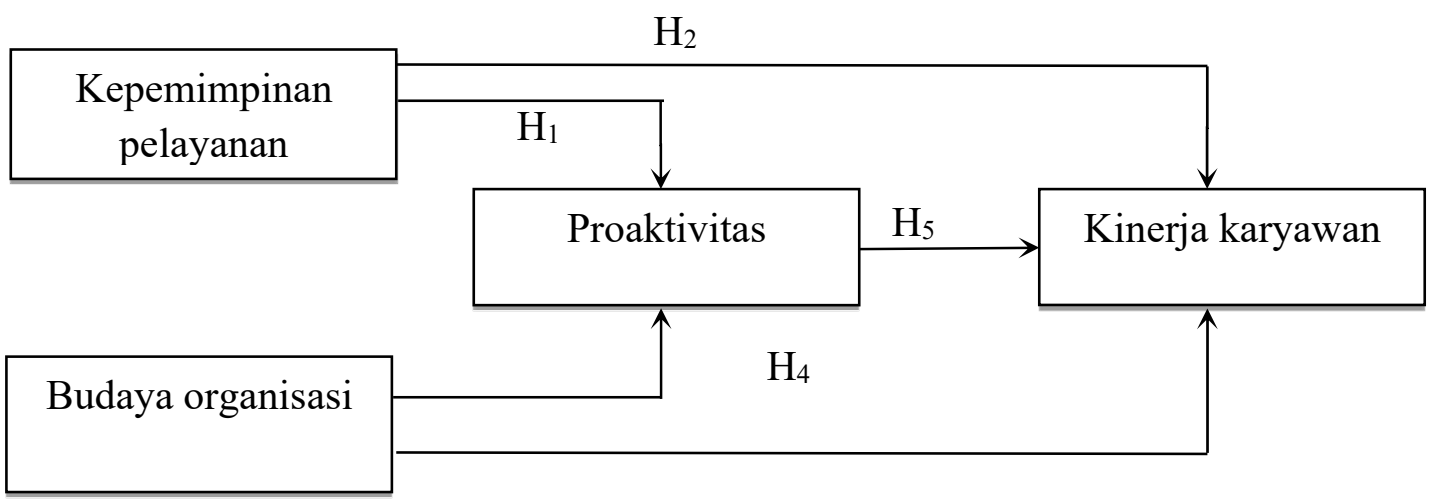

Gambar 1. Model Penelitian Empiris

\section{METODE PENELITIAN}

Sampel dan Responden

Data diperoleh dengan cara wawancara dan kuesioner dengan menggunakan pertanyaan tertutup dan terbuka dengan skala 1 sampai dengan 10 pada 30 perusahaan elektronik di Jawa Tengah. Teknik pemilihan sampel secara purposive, dengan kriteria karyawan yang telah bergabung dalam perusahaan lebih dari enam bulan. Berdasarkan kriteria tersebut terdapat 265 orang karyawan yang tergabung dalam departemen production, departemen quality assurance, departemen logistic and supply chain management, departemen marketing and customer service, dan departemen research and development.

\section{Indikator Variabel}

Variabel penelitian yang digunakan terdiri dari empat variabel yaitu: kepemimpinan, budaya organisasi, proaktivitas, dan kinerja karyawan. Variabel tersebut diukur dengan menggunakan indikator yang diadopsi dari berbagai literatur yang telah digunakan pada penelitian terdahulu.

Variabel kepemimpinan pelayanan diukur dengan lima indikator meliputi: komunikasi strategi, kepedulian, merangsang anggota, menjaga kekompakan dan menghargai perbedaan (Greenleaf, 1991). Budaya organisasi diukur dengan lima indikator meliputi: kesadaran diri, keagresifan, kepribadian, performa, dan orientasi tim (Schein, 1991). Proaktivitas diukur dengan lima indikator meliputi: inisiatif, pemanfaatan peluang, motivasi berprestasi, fokus pada perubahan, dan bertanggung jawab (Bateman dan Crant, 1993). Kinerja karyawan diukur dengan lima indikator meliputi: kuantitas, kualitas, ketepatan waktu, kemandirian, dan adaptabilitas (Armstrong, 2006). 
Artha Febriana : Kepemimpinan Pelayanan, Budaya Organisasi Dan Pengaruhnya Pada Proaktivitas Dan Kinerja Karyawan

\section{Analisis}

Analisis kualitatif dilakukan untuk melihat gambaran umum mengenai demografi dengan melihat angka indeks jawaban dan hubungan antar variabel yang selanjutnya dihubungkan dnegan jawaban pertanyaan terbuka. Analisis kuantitatif dilakukan dengan uji validitas, uji reliabilitas, uji normalitas, dan uji hipotesis menggunakan program IBM AMOS 21.

\section{HASIL DAN PEMBAHASAN \\ Hasil}

Analisis kualitatif responden berdasarkan jenis kelamin dapat diketahui bahwa karyawan didominasi oleh karyawan laki-laki. Dengan demikian dapat dipahami bahwa lakilaki merupakan pihak yang lebih banyak berurusan dengan hal-hal yag berkaitan dengan produksi, uji kualitas, logistik and supply chain management, dan riset dan pengembangan. Hasil penelitian menunjukkan bahwa keempat variabel memiliki nilai kategori indeks sedang karena berada pada rentang 40.00 sampai dengan 70.00. Variabel proaktivitas yaitu sebesar 58 , variabel kepemimpinan pelayanan yaitu sebesar 67 , variabel budaya organisasi yaitu sebesar 65 dan variabel kinerja karyawan yaitu sebesar 66.9.

Hasil pengujian reliabilitas dan validitas data menunjukkan tingkat kekonsistenan dan keakurasian yang cukup baik. Pengujian validitas dengan uji homogenitas data dengan uji korelasional antara skor masing-masing butir dengan skor total (Pearson Correlation) menunjukkan korelasi yang positif dan tingkat signifikan pada level 0,01 . Uji analisis faktor dilakukan terhadap nilai setiap variabel dengan Varimax Rotation dan nilai Kaiser's MSA menunjukkan nilai $>0,50$, artinya validitas pada masing-masing variabel cukup valid.

Hasil uji validitas dan reliabilitas menunjukkan bahwa semua instrument kuesioner adalah valid dan reliabel karena nilai korelasi $r$ hitung $>0.196$. Hasil perhitungan reliabilitas diatas menunjukkan bahwa construct reliability seluruh variabel laten memenuhi kriteria syarat cut off value $>0.70$. Demikian juga untuk nilai variance extract memenuhi syarat cut off value $>0.50$, sehingga dapat disimpulkan bahwa masing-masing variabel laten memenuhi kriteria reliabilitas.

Uji normalitas menunjukkan data berdistribusi normal dengan memperhatikan nilai c.r, skewness dan kurtosis tidak melampaui harga mutlak 2.58 yaitu sebesar 2.476 .

Tabel 1. Validity and Reliability of Measurement Items

\begin{tabular}{lc}
\hline & $\begin{array}{c}\text { Factor } \\
\text { Loading }\end{array}$ \\
\hline Kepemimpinan Pelayanan & \\
1. Komunikasi strategi & 0.82 \\
2. Kepedulian & 0.76 \\
3. Merangsang anggota & 0.60 \\
4. Menjaga kekompakan & 0.76 \\
5. Menghargai perbedaan & 0.80 \\
\hline Budaya Organisasi & \\
1. Kesadaran diri & 0.83 \\
2. Keagresifan & 0.82 \\
3. Kepribadian & 0.79 \\
4. Performa & 0.79 \\
5. Orientasi kelompok & 0.73 \\
\hline Proaktivitas & 0.89 \\
1. Inisiatif & 0.86 \\
2. Pemanfaatan peluang & \\
\hline
\end{tabular}




\begin{tabular}{ll}
\hline 3. Motivasi berprestasi & 0.77 \\
4. Fokus pada perubahan & 0.85 \\
5. Bertanggung jawab & 0.77 \\
\hline Kinerja karyawan & \\
1. Kualitas & 0.78 \\
2. Kuantitas & 0.86 \\
3. Ketepatan waktu & 0.78 \\
4. Kemandirian & 0.83 \\
5. Adaptabilitas & 0.82 \\
\hline
\end{tabular}

Uji kesesuaian model diperoleh nilai chi suare sebesar 1.132, CMIN sebesar 185.609, RMSEA sebesar 0.022, GFI sebesar 0.937, AGFI sebesar 0.919, TLI sebesar 0.993, CFI sebesar 0.994, NFI sebesar 0.950, dan PNFI sebesar 0.820.

\begin{tabular}{lcc}
\multicolumn{3}{c}{ Tabel 2. Model Fit Summary } \\
\hline $\begin{array}{c}\text { Goodness of } \\
\text { fit index }\end{array}$ & Estimate & \\
\hline CMIN & 185.609 & Fit \\
CMIN/DF & 1.132 & Fit \\
P & 0.119 & Fit \\
RMSEA & 0.022 & Fit \\
GFI & 0.937 & Fit \\
AGFI & 0.919 & Fit \\
TLI & 0.993 & Fit \\
CFI & 0.994 & Fit \\
NFI & 0.950 & Fit \\
PNFI & 0.820 & Fit \\
\hline
\end{tabular}

Berdasarkan output regression weight dalam full model terdapat lima hubungan kausalitas. Kelima hubungan memiliki nilai CR $>2.00$ dan signifikansi $<0.05$ sehingga hubungan tersebut berpengaruh signifikan maka hipotesis yang dikembangkan dapat diterima. Hasil pengujian statistik pada hipotesis 1 menunjukkan parameter estimasi sebesar 0.167 yang menunjukkan hubungan positif dan berpengaruh signifikan karena nilai CR sebesar 1.964 dan nilai signifikansi 0.049 . Hipotesis 2 menunjukkan parameter estimasi sebesar 0.183 yang menunjukkan hubungan positif dan berpengaruh signifikan karena nilai CR sebesar 3.843 dan nilai signifikansi 0.001 . Hipotesis 3 menunjukkan parameter estimasi sebesar 0.573 yang menunjukkan hubungan positif dan berpengaruh signifikan karena nilai CR sebesar 6.019 dan nilai signifikansi 0.001 . Hipotesis 4 menunjukkan parameter estimasi sebesar 0.605 yang menunjukkan hubungan positif dan berpengaruh signifikan karena nilai CR sebesar 8.651 dan nilai signifikansi 0.001 . Hipotesis 5 menunjukkan parameter estimasi sebesar 0.208 yang menunjukkan hubungan positif dan berpengaruh signifikan karena nilai CR sebesar 5.103 dan nilai signifikansi 0.001 .

Tabel 3. Regression Weight Full Model

\begin{tabular}{lclcccc}
\hline & & & Estimate & S.E. & C.R. & $\boldsymbol{P}$ \\
\hline Proaktivitas & $<---$ & Kepemimpinan_Pelayanan & .167 & .085 & 1.964 & .049 \\
Kinerja_Karyawan & $<--$ & Kepemimpinan_Pelayanan & .183 & .048 & 3.843 & .001 \\
Proaktivitas & $<---$ & Budaya_Organisasi & .573 & .095 & 6.019 & .001 \\
Kinerja_Karyawan & $<---$ & Budaya_Organisasi & .605 & .070 & 8.651 & .001 \\
Kinerja_Karyawan & $<---$ & Proaktivitas & .208 & .041 & 5.103 & .001 \\
\hline
\end{tabular}


Artha Febriana : Kepemimpinan Pelayanan, Budaya Organisasi Dan Pengaruhnya Pada Proaktivitas Dan Kinerja Karyawan

\section{Pembahasan \\ Kepemimpinan pelayanan memiliki pengaruh positif pada proaktivitas dan kinerja karyawan}

Hasil pengujian hipotesis 1 menyatakan bahwa semakin kuat kepemimpinan pelayanan maka semakin kuat proaktivitas karyawan dapat diterima. Hal ini berarti bahwa kepemimpinan pelayanan memiliki pengaruh positif terhadap proaktivitas karyawan. Adanya pengaruh positif kepemimpinan pelayanan terhadap proaktivitas karyawan menunjukkan bahwa pemimpin mampu mengartikulasi misi bersama dengan cara membangkitkan inspirasi anggota. Kecakapan pemimpin dalam menginspirasi dan memotivasi secara konsisten berkorelasi tinggi dengan meningkatnya inisiatif anggota dalam bekerja (Winkle et al, 2014). Meningkatnya kemampuan anggota dalam mengambil inisiatif, anggota akan memiliki peluang-peluang baru dan bertanggung jawab untuk melakukan segala perubahan demi kemajuan bersama (Ozyilmaz, 2015).

Kepemimpinan pelayanan memiliki pengaruh positif terhadap proaktivitas. Semakin kuat kepemimpinan pelayanan terhadap anggota menunjukkan bahwa pemimpin mampu menginspirasi anggota untuk bekerja keras guna menyelesaikan tugas-tugasnya secara efektif dan demi mencapai kemajuan bersama (Coetzer, 2017). Pemimpin sebagai pengaruh, seni atau proses untuk mempengaruhi anggota agar mereka mau bekerjasama dan antusias ke depan untuk mencapai tujuan bersama (Brohi et al., 2018).

Pemimpin memainkan peranan penting dalam menciptakan visi secara menarik, pemimpin dan anggota merumuskan bersama kearah peningkatan di masa mendatang, menginspirasi, memotivasi dan memberikan energi untuk bergerak melakukan perubahan positif (Rashid et al, 2017). Pemimpin yang menginspirasi akan menciptakan resonansi serta menggerakkan anggota dengan visi yang menyemangati dan misi bersama (Bodewes, 2011).

Pemimpin yang merupakan change champion yang handal mampu menjalin hubungan dengan anggota dan memahami ketakutan atau keraguan apa yang mereka miliki mengenai perubahan tertentu akan mempengaruhi dan meningkatkan antusias anggota terhadap perubahan (Reinke, 2004).

Kemampuan pemimpin dalam mempersatukan para bawahannya mampu menciptakan sinergi yang positif di masa mendatang. Pemimpin membangun, mengembangkan, dan meningkatkan daya atau kekuasaan melalui kerjasama, berbagi, dan bekerja bersama (Luo dan Zheng, 2018). Pemimpin mampu mempengaruhi anggota untuk berinisiatif dan bertindak untuk menghasilkan suatu pola yang konsisten dalam rangka mencari jalan pemecahan dari suatu persoalan bersama (Walumbwa dan Oke, 2010).

Hasil pengujian hipotesis 2 menyatakan bahwa semakin kuat kepemimpinan pelayanan maka semakin kuat kinerja karyawan dapat diterima. Hal ini berarti bahwa kepemimpinan pelayanan memiliki pengaruh positif terhadap kinerja karyawan. Kepemimpinan pelayanan melaksanakan fungsi konstruktif atau perubahan adaptif dengan mengembangkan pola pikir anggotanya sehingga kinerja mereka melebihi batasan-batasan kreativitas lama (Parris dan Peachey, 2012). Pemimpin meningkatkan kinerja anggota, menjadikan mereka lebih baik dari sebelumnya (Marketti dan Kozar, 2007). Pemimpin meningkatkan produktivitas anggota dan juga kemandirian, dan adaptabilitas (Peterson dan Galvin, 2012).

Kepemimpinan pelayanan memiliki pengaruh positif terhadap kinerja karyawan. Semakin kuat kepemimpinan pelayanan terhadap anggota menunjukkan bahwa pemimpin mampu menginspirasi anggota untuk melakukan pekerjaan dengan baik (volume yang lebih besar, efisiensi tinggi, dan produktivitas yang lebih tinggi) (Dierendonck, 2011). 
Pemimpin memainkan peranan penting dalam membimbing dan memotivasi anggota untuk selalu meningkatkan efektivitas kinerja yang diukur oleh kuantitas, kualitas, dan ketepatan waktu yang diterima atau ditetapkan sebelumnya (Wang dan Poutziouris, 2010).

Kemampuan pemimpin dalam mengembangkan pola pikir anggota sehingga melebihi batasan-batasan kreativitas (Valdiserri dan Wilson, 2010). Pemimpin meningkatkan kinerja anggota, menjadikan mereka lebih baik dari sebelumnya (Sendjaya et al, 2008). Pemimpin meningkatkan rasa percaya diri dan harapan-harapan yang membuat mereka menunjukkan kualitas terbaik mereka (Liden et al, 2008).

$\mathrm{H}_{1}$ : Kepemimpinan pelayanan memiliki pengaruh positif pada proaktivitas

$\mathrm{H}_{2}$ : Kepemimpinan pelayanan memiliki pengaruh positif pada kinerja karyawan

\section{Budaya organisasi memiliki pengaruh positif pada proaktivitas dan kinerja karyawan}

Hasil pengujian hipotesis 3 menyatakan bahwa semakin kuat budaya organisasi maka semakin kuat proaktivitas karyawan dapat diterima. Hal ini berarti bahwa budaya organisasi memiliki pengaruh positif terhadap proaktivitas karyawan. Budaya organisasi sebagai seperangkat asumsi yang dibangun dan dianut bersama oleh organisasi sebagai moral dalam beradaptasi dengan lingkungan eksternal dan proses integrasi internal (Griffin dan Parker, 2007; Greguras dan Diefendorff, 2010)). Budaya organisasi merupakan pola dari keyakinan, perilaku, dan nilai-nilai yang dimiliki bersama membentuk cara anggota berperilaku, berinteraksi, dan bekerja (Andrew et al., 2005; Grant dan Ashford, 2008)). Nilai merupakan keinginan efektif, kesadaran, atau keinginan yang membimbing perilaku dalam meningkatkan inisiatif anggota dalam bekerja (Catherine dan Cheryl, 2007). Meningkatnya kemampuan anggota dalam mengambil inisiatif, anggota akan memiliki peluang-peluang baru dan bertanggung jawab untuk melakukan segala perubahan demi kemajuan bersama (Chadha dan Sharma, 1991; Fuller dan Marler, 2009).

Budaya organisasi memiliki pengaruh positif terhadap proaktivitas. Budaya organisasi yang kuat akan meningkatkan kontribusi dan tanggung jawab (Chadha dan Kaur, 1988; Frese dan Fay, 2001). Budaya organisasi mendorong keterlibatan semua anggota untuk bekerja sama guna menciptakan atau membentuk suatu nilai dengan pemahaman bahwa nilai tersebut dapat tercapai secara efisien apabila semuanya bekerja sama dari pada bekerja secara individual (Wu et al, 2017). Budaya organisasi membangkitkan kepercayaan diri, suasana keterbukaan, mau menerima pendapat orang lain serta terpeliharanya suasana intrapreneurial (Thomas dan Viswesvaran, 2010). Budaya organisasi menciptakan iklim kepercayaan, loyalitas, dan komunikasi (Ryan \&Deci, 2000). Budaya organisasi dalam proses pembuatan keputusan akan memunculkan perasaan sense of ownership (Parker et al., 2010). Anggota saling mendukung, saling tolong menolong, proaktif, dan saling membantu (Ohly dan Fritz, 2010). Anggota akan memiliki sikap positif, optimis, kooperatif, dan suportif terhadap visi dan misi perusahaan (Kickul dan Gundry, 2002). Anggota memiliki sikap can do, presistensi, harmoni, mempunyai kemauan dan tekad melakukan apapun yang diperlukan untuk mencapai misi (Morrison dan Phelps, 1999).

Hasil pengujian hipotesis 4 menyatakan bahwa semakin kuat budaya organisasi maka semakin kuat kinerja karyawan dapat diterima. Hal ini berarti bahwa budaya organisasi memiliki pengaruh positif terhadap kinerja karyawan. Budaya organisasi yang kuat memiliki nilai-nilai bersama yang dipahami secara mendalam, dianut, dan diperjuangkan oleh para anggota perusahaan (Awadh dan Saad, 2013). Budaya yang positif dan kuat sangat berpengaruh terhadap perilaku dan efektivitas karyawan dalam bekerja, pada gilirannya akan meningkatkan kinerja dan keberhasilan organisasi (Ernst, 2001; Ahmed dan Shafiq, 2014). Anggota dalam organisasi akan menganggap aturan bukan lagi sebagai kewajiban yang membelenggu namun sudah menjadi kebutuhan (Kopelman dan Guzzo, 1990). Di sisi lain, mereka memiliki rasa kebersamaan, kekeluargaan, dan bangga pada organisasinya yang pada 
Artha Febriana : Kepemimpinan Pelayanan, Budaya Organisasi Dan Pengaruhnya Pada Proaktivitas Dan Kinerja Karyawan

gilirannya menciptakan lingkungan yang kondusif bagi peningkatan kinerja karyawan (Kotter, 2012).

Budaya organisasi memiliki pengaruh positif terhadap kinerja karyawan. Budaya organisasi secara khusus mendatangkan output yang lebih baik (Kotter dan Heskett, 1992). Budaya organisasi merupakan proses sosial dimana anggota menjadi lebih terlibat dalam organisasi dan ingin melihat pekerjaannya berhasil, memungkinkan anggota memahami dan berkontribusi terhadap pekerjaanya (Rajendar dan Junma, 2005). Anggota akan lebih sering mengajukan saran untuk perbaikan kualitas maupun kuantitas (Nikpour, 2017). Anggota dilibatkan dalam proses pengambilan keputusan akan mempengaruhi rasa tanggung jawab dan wellbeing. Anggota berusaha melakukan perbaikan secara terus menerus baik dalam kualitas, produktivitas, dan pelayanan kepada pelanggan dengan lebih baik (Denision dan Mishra, 1995; Ogaard dan Marnburg, 2005). Pemberian tanggung jawab menunjukkan bahwa anggota mampu meningkatkan produktivitas yang mengarah pada terciptanya efisiensi dan efektivitas (Shahzad et al, 2012; Ng'ang dan Nyongesa, 2012; Ghorbanhosseini, 2013).

$\mathrm{H}_{3}$ : Budaya organisasi memiliki pengaruh positif pada proaktivitas

$\mathrm{H}_{4}$ : Budaya organisasi memiliki pengaruh positif pada kinerja karyawan

\section{Proaktivitas memiliki pengaruh positif terhadap kinerja karyawan}

Hasil pengujian hipotesis 5 menyatakan bahwa semakin kuat proaktivitas karyawan maka semakin kuat pula kinerja karyawan dapat dihasilkan. Hal ini berarti bahwa proaktivitas karyawan dalam bekerja bertendensi meningkatkan kinerja. Proaktivitas digambarkan sebagai variabel penting sebagai penentu keberhasilan perusahaan dan juga merupakan penentu yang mengarah kepada peningkatan efektivitas perusahaan (Ashford dan Black, 1996). Perilaku aktif para karyawan dalam berinisiatif (menciptakan ide-ide baru), oportunitis, berani bertindak dan tekun akan menciptakan perubahan positif dalam lingkungan kerja (Bateman dan Crant, 1993). Karyawan akan bertanggung jawab atas perilaku pribadi, dan menetapkan tujuan berdasarkan prinsip serta nilai-nilai (Fuller \& Marler, 2009). Ketika karyawan dapat menetapkan tujuan sendiri, mereka dapat melampaui tugas yang ditetapkan dan memiliki fokus jangka panjang pada pekerjaannya (Grant \&Ashford, 2008).

Proaktivitas memiliki memiliki pengaruh positif terhadap kinerja karyawan. Semakin kuat proaktivitas akan meningkatkan dorongan prestasi dalam karyawan (Greguras \& Diefendorff, 2010). Proaktivitas dalam bekerja berdampak dalam meningkatkan sinergi secara positif dan terkoordinir menghasilkan satu tingkat kinerja yang lebih tinggi (Griffin \& Parker, 2007). Proaktivitas akan meningkatkan interaksi dan saling bergantung informasi, sumber daya, keterampilan, serta berusaha untuk menggabungkan upaya mereka untuk mencapai tujuan bersama, dimana setiap anggota berbagi tanggung jawab untuk mencapainya serta setiap anggota memahami dan merasa terikat (Kickul \& Gundry, 2002). Karyawan berkinerja unggul memiliki kebersamaan tujuan, tanggung jawab bersama, responsif, inovatif dan kreatif, komunikatif, berfokus pada tugas, dan pemecahan masalah (Morrison \& Phelps, 1999).

$\mathrm{H}_{5}$ : Proaktivitas memiliki pengaruh positif pada kinerja karyawan

\section{SIMPULAN}

Hasil penelitian menunjukkan bahwa kinerja yang dicapai oleh karyawan termasuk dalam kategori rendah (dilihat dari koefisien kausalitas terhadap kinerja karyawan), disebabkan oleh rendahnya proaktivitas (peran aktif) dari karyawan dalam bekerja. Untuk meningkatkan proaktivitas dan kinerja karyawan maka perusahaan perlu meningkatkan kepemimpinan pelayanan dan budaya organisasi. Kepemimpinan pelayanan mengarahkan dan menuntun pada sutu visi sepanjang waktu serta mengembangkan kepemimpinan masa depan dan budaya organisasional (Russel dan Stone, 2002). Pemimpin pelayanan 
menciptakan budaya-budaya organisasi yang memberdayakan para anggotanya untuk mencapai tujuan bersama (Sendjaya dan Sarros, 2002).

Pemimpin harus memiliki ketrampilan atau kemampuan memimpin, terutama mampu membangun komunikasi dengan baik, peduli terhadap anggota, mampu merangsang bawahan, mampu menjaga kekompakan, dan menghargai perbedaan (Sendjaya et al., 2008). Pemimpin yang berorientasi pada anggota mampu membangun, mengembangkan, dan meningkatkan inisiatif anggota dalam bekerja (Marketti dan Kozar, 2007). Dengan meningkatkan kemampuan anggota dalam mengambil inisiatif, anggota akan memiliki peluang-peluang baru dan bertanggung jawab untuk melakukan segala perubahan demi kemajuan bersama (Peterson dan Galvin, 2012).

Pemimpin menetapkan berbagai nilai dan norma yang dipraktikkan oleh perusahaan (Awadh dan Saad, 2013). Keefektifan penyebarluasan dan penanaman nilai-nilai inti budaya sangat tergantung pada komitmen pemimpin, terutama dalam memainkan peran sebagai panutan (Ernst, 2001). Pemimpin perlu menguatkan budaya organisasi sebab budaya organisasi yang kuat mendukung tujuan-tujuan perusahaan (Kotter, 2012). Dalam perusahaan dengan budaya yang kuat, nilai-nilai bersama dipahami secara mendalam, dianut, dan diperjuangkan oleh para anggota perusahaan. Budaya yang kuat dan positif sangat berpengaruh terhadap perilaku dan efektivitas kinerja di perusahaan (Rajendar \& Junma, 2005).

\section{DAFTAR PUSTAKA}

Ahmed \& Shafiq. 2014. The impact of organizational culture on organizational performance: a case study of Telecom sector. Global journal of management and business research.

Amstrong. 2006. Performance management: Key Strategies and Practical Guidelines. London and Philadelphia: Kogan Page.

Andrew \& Malcolm. 2005. Do Organizational Climate and Competitive Strategy Moderate the Relationship between Human Resource Management and Productivity. Journal of Management.

Ashford \& Black. 1996. Proactivity during organizational entry: The role of desire for control. Journal of Applied Psychology.

Audrey \& Patrice. 2012. Adaptive performance: A new scale to measure individual performance in organizations. Canadian Journal of Administrative Sciences

Awadh \& Saad. 2013. Impact of Organizational Culture on Employee Performance. International Review of Management and Business Research.

Baard et al. 2014. Performance adaptation: A theoretical integration and review. Journal of Management.

Bass. 1985. Leadership and performance beyond expectations. New York, Free Press.

Bateman \& Crant. 1993. The proactive component of organizational behavior: A measure and correlates. Journal of Organizational Behavior

Bodewes. 2011. The mediating effect of regulatory focus on the relation between leadership style and employee creativity and in role performance. Leadership and employee behavior in organizations.

Brohi et al. 2018. The impact of servant leadership on employee attitudinal and behavioural outcomes. Congent business and management.

Burns. 1978. Leadership, Harper \& Row, New York.

Catherine \& Cheryl. 2007. Perceptions of Organizational Culture, Leadership Effectiveness and Personal Effectiveness across Six Countries. Journal of International Management.

Chadha \& Sharma. 1991. Job Satisfaction and Organizational Climate Among Public and Private Sector Organizations. Perspectives in Psychological Researches. 
Artha Febriana : Kepemimpinan Pelayanan, Budaya Organisasi Dan Pengaruhnya Pada Proaktivitas Dan Kinerja Karyawan

Chadha \& Kaur. 1988. Correlational Study of Organizational Climate with Job involvement and Job Satisfaction in a Public Sector Organization. Asian Journal of Psychology and Education.

Chung. 2009. The Exploration of Relationship between Organizational Culture and Style of Leadership. IEEE.

Coetzer et al. 2017. Servant leadership and work related wellbeing in a construction company. SA Journal of industrial psychology.

Crant \& Wang. 2011. Dispositional antecedents of demonstration and usefulness of voice behavior. Journal of Business and Psychology.

Denision \& Mishra. 1995. Toward a theory of organizational culture and effectiveness

Dierendonck. 2011. Servant leadership: A review and synthesis. Journal of Management.

Ernst. 2001. Corporate culture and innovative performance of a firm. Management of Engineering and technology

Farling et al. 1999. Servant leadership: Setting the stage for empirical research. Journal for Leadership Studies.

Fuller \& Marler. 2009. Change driven by nature: A meta-analytic review of the proactive personality literature. Journal of Vocational Behavior.

Ghorbanhosseini. 2013. The effect of organizational culture, teamwork and organizational development on organizational commitment: The mediating role of human capital.

Grant \& Ashford. 2008. The dynamics of proactivity at work. Research in Organizational Behavior.

Greenleaf. 1991. The servant as leader. Indianapolis, IN: The Robert K. Greenleaf Center.

Greguras \& Diefendorff. 2010. Why does proactive personality predict employee life satisfaction and behaviors? A field investigation of the mediating role of the selfconcordance model. Personnel Psychology.

Griffin \& Parker. 2007. A new model of work role performance: Positive behavior in uncertain and interdependent contexts. Academy of Management Journal

Conger \& Kanungo. 1988. The empowerment process: Integrating theory and practice. Academy of Management Review.

Jeremy \& Ciller. 2012. Perceived leadership style and employee participation in a manufacturing company in the democratic republic of Congo. African journal of business management.

Kickul \& Gundry. 2002. Prospecting for strategic advantage: The proactive entrepreneurial personality and small firm innovation. Journal of Small Business Management.

Kotter. 2012. Corporate culture and performance. New York: Free press.

Kotter \& Heskett. 1992. Corporate Culture and Performance. New York: Free press.

Liden et al. 2008. Servant leadership: Development of a multidimensional measure and multilevel assessment. The Leadership Quarterly.

Linton. 2003. An Examination Of The Relationships Between Leadership Style, Quality and Employee Satisfaction In R\&D Environments. IEEE.

Luo \& Zheng. 2018. The impact servant leadership on proactive behaviors: A study based on cognitive evaluation theory. Scientific research publishing.

Luthans. 1992. Organizational Behaviour. McGraw Hill Book Company, Fifth Edition.

Marcketti \& Kozar. 2007. Leading with relationships: A small firm example. Learning Organization.

Moorhead \& Griffin. 1994. Organisational Behaviour: Managing People and Organisations. India.

Morrison \& Phelps. 1999. Taking charge at work: Extrarole efforts to initiate workplace change. Academy of Management Journal. 
Ng'ang'a \& Nyongesa. 2012. The impact of organizational culture on performance of educational institutions. International Journal of Business \& Social Science.

Nikpour, 2017. The impact of organizational culture on organizational performance: the mediating role of employees organizational commitment. Int. journal of organizational leadership.

Øgaard et al. 2005. Organizational culture and performance- evidence from the fast food restaurant industry. Food Service Technology

Ohly \& Fritz. 2010. Work characteristics, challenge appraisal, creativity, and proactive behavior: A multi-level study. Journal of Organizational Behavior

Omolayo. 2007. Effect of Leadership Style on Job-Related Tension and Psychological Sense of Community in Work Organizations: A Case Study of Four Organizations in Lagos State, Nigeria, Bangladesh. e-Journal of Sociology.

Ozyilmaz. 2015. How does servant leadership affect employee attitudes, behaviors, and psychological climates in a for profit organizational context? Journal of management and organization.

Parker et al. 2010. Making things happen: A model of proactive motivation. Journal of Management.

Parker \& Collins. 2010. Taking stock: Integrating and differentiating multiple proactive behaviors. Journal of Management.

Parker et al. 2006. Modeling the antecedents of proactive behavior at work. Journal of Applied Psychology.

Parris \& Peachey. 2012. A systematic literature review of servant leadership theory in an organizational context. Journal of Business Ethics.

Peterson \& Galvin. 2012. CEO servant leadership: Exploring executive characteristics and firm performance. Personnel psychology.

Sashid et al. 2017. Relationship of servant leadership with employee in role and extra role performance in GLC'S of Malaysia. City University Research Journal.

Rajendar \& Jun Ma. 2005. Benchmarking Culture and Performance in Chinese Organizations. Benchmarking an International Journal.

Reinke. 2004. Service before Self: Towards a Theory of Servant-Leadership. Global Virtue Ethics Review

Russell \& Stone. 2002. A review of servant leadership attributes: Developing a practical model. Leadership \& Organization Development Journal.

Sendjaya \& Sarros. 2002. Servant Leadership: Its Origin, Development and Application in Organizations. Journal of Leadership and Organizational Studies.

Sendjaya et al. 2008. Defining and measuring servant leadership behaviour in organizations. Journal of Management Studies.

Stone et al. 2003. Transformational versus servant leadership: a difference in leader focus. Leadership \& Organisation Journal.

Thomas \& Viswesvaran. 2010. Employee proactivity in organizations: A comparative metaanalysis of emergent proactive constructs. Journal of Occupational and Organizational Psychology

Valdiserri \& Wilson. 2010. The study of leadership in small business organizations: Impact on profitability and organizational success. The Entrepreneurial Executive.

Walumbwa \& Oke. 2010. Servant Leadership, Procedural Justice Climate, Service Climate, Employee Attitudes, and Organizational Citizenship Behavior: A Cross-Level Investigation. Journal of Applied Psychology

Wang et al. 2009. The Mechanism of Leadership Styles Affecting Team Innovation in the PRC. IEEE. 
Artha Febriana : Kepemimpinan Pelayanan, Budaya Organisasi Dan Pengaruhnya Pada Proaktivitas Dan Kinerja Karyawan

Wang \& Poutziouris. 2010. Leadership styles, management systems and growth: Empirical evidence from UK owner-managed SMEs. Journal of Enterprising Culture.

Wingkle et al. 2014. Relationship between the servant leadership behavior of immediate supervisors and followers perceptions of being empowered in context of small business. Journal of leadership education.

Wu et al. 2017. Enhancing a sense of competence at work by engaging in proactive behavior: the role of proactive personality. Journal of happiness study. 